\title{
Chronic Obstructive Pulmonary Disease Phenotypes
} The Future of COPD

\author{
MeiLan K. Han 1 , Alvar Agusti ${ }^{3}$, Peter M. Calverley4, Bartolome R. Celli ${ }^{5}$, Gerard Criner ${ }^{6}$, Jeffrey L. Curtis ${ }^{1,7}$, \\ Leonardo M. Fabbri ${ }^{8}$, Jonathan G. Goldin9, Paul W. Jones ${ }^{10}$, William MacNee ${ }^{11}$, Barry J. Make ${ }^{12}$, Klaus F. Rabe ${ }^{13}$, \\ Stephen I. Rennard ${ }^{14}$, Frank C. Sciurba ${ }^{15}$, Edwin K. Silverman ${ }^{5,16}$, Jørgen Vestbo ${ }^{17}$, George R. Washko ${ }^{5}$, \\ Emiel F. M. Wouters ${ }^{18}$, and Fernando J. Martinez ${ }^{2}$
}

\begin{abstract}
${ }^{1}$ Division of Pulmonary and Critical Care Medicine, University of Michigan Health System, Ann Arbor, Michigan; ${ }^{2}$ Thorax Institute, Hospital Clinic, University of Barcelona, Barcelona, Spain; ${ }^{3}$ CIBER Enfermedades Respiratorias, Fundació Caubet-Cimera, Spain; ${ }^{4}$ School of Clinical Sciences, University of Liverpool, Liverpool, United Kingdom; ${ }^{5}$ Division of Pulmonary and Critical Care, and ${ }^{16}$ Channing Laboratory and Center for Genomic Medicine, Brigham and Women's Hospital, Harvard Medical School, Boston, Massachusetts; ${ }^{6}$ Division of Pulmonary and Critical Care Medicine, Temple Lung Center, Temple University School of Medicine; ${ }^{7}$ Division of Pulmonary and Critical Care Medicine, Ann Arbor VA Healthsystem, Ann Arbor, Michigan; ${ }^{8}$ Department of Oncology, Haematology and Pulmonary Diseases, University of Modena and Reggio Emilia, Policlinico di Modena, Modena, Italy; ${ }^{9}$ Department of Radiology, David Geffen School of Medicine, University of California Los Angeles, Los Angeles, California; ${ }^{10}$ Division of Clinical Science, St. George's Hospital Medical School, London, England; ${ }^{11}$ ELEGI Colt Research Labs, The Queen's Medical Research Institute, University of Edinburgh, Edinburgh, Scotland; ${ }^{12}$ Division of Pulmonary and Critical Care, National Jewish Health, University of Colorado Denver School of Medicine, Denver, Colorado; ${ }^{13}$ Department of Pulmonology, Leiden University Medical Center, Leiden, The Netherlands; ${ }^{14}$ Division of Pulmonary and Critical Care, University of Nebraska Medical Center, Omaha, Nebraska; ${ }^{15}$ Division of Pulmonary and Critical Care, University of Pittsburgh Medical Center, Pittsburgh, Pennsylvania; ${ }^{17}$ Manchester Academic Health Sciences Centre, University of Manchester, Manchester, United Kingdom; and ${ }^{18}$ Department of Respiratory Medicine, University Hospital Maastricht, Maastricht University, Maastricht, The Netherlands
\end{abstract}

Significant heterogeneity of clinical presentation and disease progression exists within chronic obstructive pulmonary disease (COPD). Although $\mathrm{FEV}_{1}$ inadequately describes this heterogeneity, a clear alternative has not emerged. The goal of phenotyping is to identify patient groups with unique prognostic or therapeutic characteristics, but significant variation and confusion surrounds use of the term "phenotype" in COPD. Phenotype classically refers to any observable characteristic of an organism, and up until now, multiple disease characteristics have been termed COPD phenotypes. We, however, propose the following variation on this definition: "a single or combination of disease attributes that describe differences between individuals with COPD as they relate to clinically meaningful outcomes (symptoms, exacerbations, response to therapy, rate of disease progression, or death)." This more focused definition allows for classification of patients into distinct prognostic and therapeutic subgroups for both clinical and research purposes. Ideally, individuals sharing a unique phenotype would also ultimately be determined to have a similar underlying biologic or physiologic mechanism(s) to guide the development of therapy where possible. It follows that any proposed phenotype, whether defined by symptoms, radiography, physiology, or cellular or molecular fingerprint will require an iterative validation process in which "candidate" phenotypes are identified before their relevance to clinical outcome is determined. Although this schema represents an ideal construct, we acknowledge any phenotype may be etiologicaxlly heterogeneous and that any one individual may manifest multiple phenotypes. We have much yet to learn, but establishing a common language for future research will facilitate our understanding and management of the complexity implicit to this disease.

Keywords: prognosis; mortality; decline; therapy; outcomes

(Received in original form December 11, 2009; accepted in final form June 2, 2010) Correspondence and requests for reprints should be addressed to MeiLan K. Han, M.D., M.S., University of Michigan - Pulmonary and Critical Care, 1500 E. Medical Center Drive, 3916 Taubman, Ann Arbor, Ml 48109. E-mail: mrking@umich.edu

Am J Respir Crit Care Med Vol 182. pp 598-604, 2010

Originally Published in Press as DOI: 10.1164/rccm.200912-1843CC on June 3, 2010 Internet address: www.atsjournals.org

\section{AT A GLANCE COMMENTARY}

Scientific Knowledge on the Subject

Significant heterogeneity of clinical presentation and disease progression exists within chronic obstructive pulmonary disease (COPD). Although $\mathrm{FEV}_{1}$ inadequately describes this heterogeneity, a clear alternative has not emerged.

What This Study Adds to the Field

We propose that COPD phenotypes should be associated with clinically meaningful outcomes. This more focused definition allows for classification of patients into distinct prognostic and therapeutic subgroups for both clinical and research purposes. Establishing a common language for future research will facilitate our understanding and management of this disease.

The diagnosis, assessment and management of chronic obstructive pulmonary disease (COPD) are currently facing an important dilemma. On the one hand, COPD is defined by the presence of airflow limitation that is not fully reversible, and its treatment is mostly guided by the severity of this limitation (1). On the other hand, it is now widely recognized that COPD is a complex syndrome with numerous pulmonary and extrapulmonary components. Importantly, significant heterogeneity exists with respect to clinical presentation, physiology, imaging, response to therapy, decline in lung function, and survival. As a result, there is consensus that $\mathrm{FEV}_{1}$ by itself does not adequately describe the complexity of the disease and that $\mathrm{FEV}_{1}$ cannot be used in isolation for the optimal diagnosis, assessment, and management of the disease. However, a clear alternative has not yet been defined. Considering that almost all we currently know about pathophysiology, mechanism, and response to treatment is regarding COPD caused by or associ- 
ated with cigarette smoking, the discussion that follows relates only to COPD observed in smokers.

The identification and subsequent grouping of key elements of the COPD syndrome into clinically meaningful and useful subgroups (phenotypes) that can guide therapy more effectively is a potential solution to this dilemma. Caution, however, is warranted when clustering patients with similar symptoms and clinical manifestations, as phenotyping in COPD is still a relatively young endeavor as compared with other fields. The novelty of COPD phenotyping is illustrated by the fact that a MEDLINE search revealed just over 400 phenotyping papers published in the field of COPD, whereas, for instance, it identifies more than 5,000 in breast cancer. Moreover, there is significant variation, confusion, and uncertainty surrounding use of the term phenotype in COPD. A common language for future research should facilitate our understanding of the heterogeneity implicit to this disease and help us design better alternatives for the prevention and management of the disease. This article discusses and refines the concept of phenotyping in COPD and presents a possible schema that can serve as a framework for future research.

\section{COPD PHENOTYPES: AN OPERATIONAL DEFINITION}

The classic definition of a phenotype reflects the observable structural and functional characteristics of an organism determined by its genotype and modulated by its environment: the interactions between "nature" and "nurture" (2). Although this definition has been historically useful in a variety of contexts (3), in medicine in general, and in COPD in particular, we believe this concept must be refined to more efficiently fulfill the following clinical and research goals. From a clinical and patient-centered perspective, a COPD phenotype should be able to classify patients into distinct subgroups that provide prognostic information and allow us to better determine appropriate therapy that alters clinically meaningful outcomes. From a research standpoint, phenotyping should allow us to select a uniform group of patients and assess the most important outcome measures in that group for therapeutic clinical trials. Phenotypes can also form the basis for biological mechanistic investigations. Hence the ultimate goal of phenotyping in medicine is to allow the identification of patient groups with unique prognostic or therapeutic characteristics. In COPD until now, disease characteristics and/or disease severity have frequently been termed COPD phenotypes (3).

Accordingly, we propose the following variation on the traditional definition of a phenotype: "a single or combination of disease attributes that describe differences between individuals with COPD as they relate to clinically meaningful outcomes (symptoms, exacerbations, response to therapy, rate of disease progression, or death)." In other words, it is proposed that phenotypes in COPD should have real predictive value. It follows, therefore, that any proposed phenotype must be prospectively validated and refined for each of the outcomes to which it relates. Identifying the outcome is important as certain attributes, such as dyspnea, depression, or exacerbations, could be viewed as outcomes or phenotypes depending on the clinical context.

Ideally, individuals clustering within a unique phenotype and exhibiting similar clinical outcomes should also exhibit a similar therapeutic response profile because of a similar underlying biologic or physiologic mechanism. At this point in time, however, the field of COPD phenotyping has not yet reached the stage at which we have significant understanding regarding the mechanism(s) behind every clinical presentation. We therefore believe that at this juncture, the proposed approach represents the best way forward. Ideally, by identifying patient subgroups that have unique characteristics as they relate to clinically meaningful outcomes, we may ultimately discover the etiologic mechanisms. However, it should also be pointed out that an understanding of mechanism is not necessarily required to significantly benefit patients and that the process of phenotype validation is an iterative one. As an example from the field of cardiology, the clinical effects of HMG-CoA reductase inhibitors (statins) were initially believed to be due largely to their cholesterol-lowering effect. Clinical trials, however, revealed benefit beyond what might be expected from changes in lipid levels alone, suggesting that statins likely have pleiotropic effects. This has led to further clinical trials, and the subgroup of patients who might benefit from statins has expanded from those with elevated cholesterol to those with elevated CRP. In COPD, the National Emphysema Treatment Trial identified a subgroup of patients with upper lobe-predominant emphysema and low exercise capacity who benefit from lung volume reduction surgery (LVRS), although a mechanistic explanation for benefit in this specific subgroup is not readily obvious. Such examples indicate how similar clinical response can identify phenotypes with immediate and direct implications for patients in the absence of a well-defined mechanism.

It should be noted, however, that not all outcomes may be modifiable by (current) therapy, and that some outcomes may arise from multiple etiologic mechanisms. Furthermore, response to therapies can also be difficult to measure reliably and many of the treatments and measures we typically use (for example, $\mathrm{FEV}_{1}$ ) may not be specific, well targeted, or sensitive enough to uniquely identify a phenotypic subgroup.

\section{POTENTIAL PHENOTYPES}

Here we discuss how disease attributes fit within the phenotyping framework we have proposed. As patient outcomes are a key component of the operational definition of phenotype proposed above, potential phenotypes are discussed within the clinical outcomes to which they relate.

\section{Clinical Manifestations}

Age, smoking history, sex, and ethnicity may all significantly impact disease presentation and progression. For example, lung function declines with increasing age (4). Female sex appears to be associated with worse quality of life (QOL) and higher rates of depression and anxiety; data suggest female sex may also be associated with higher susceptibility to the toxic effects of smoking (5). Women may also differ from men in the extent and distribution of airway abnormality and emphysema (5), which in themselves are not clinically relevant outcomes, but may relate to clinically relevant outcomes (see Radiologic Characterization section below). Body composition and dyspnea can be assessed with various instruments, and both descriptors appear to have independent prognostic value either as sole measures or as components of the body mass index (BMI), airflow obstruction, dyspnea, and exercise capacity (BODE) Index (6). Similarly, depression and anxiety have been independently associated with an increased frequency of hospital admissions and COPD exacerbation relapses $(7,8)$.

\section{Physiological Manifestations}

Spirometric indices, including $\mathrm{FEV}_{1}, \mathrm{FVC}$, and their ratio, are used to define the presence and severity of disease. Unfortunately, these features explain less than 10 to $25 \%$ of the disease impact on patient symptoms, QOL, and exercise performance (9-11). Rapid physiologic progression as indicated by change in 
$\mathrm{FEV}_{1}$, however, may indicate a distinct phenotype. Rapid decline in $\mathrm{FEV}_{1}$ is not only predictive of morbidity, mortality, and hospitalization rates (12) but has also been linked to distinct plasma biomarker signatures (13). Bronchodilator reversibility and airway hyperresponsiveness are highly variable in patients with COPD from patient to patient, and also within a given patient when measured serially over time, and thus have limited sensitivity or specificity in distinguishing COPD from asthma $(14,15)$. Airway hyperresponsiveness has been associated with a greater longitudinal decline in lung function; bronchodilator reversibility defined as change in $\mathrm{FEV}_{1}$ may be less common with an emphysema-dominant phenotype $(14,16)$. Hyperinflation may also define patient groups associated with varying mortality or functional impairment $(17,18)$. Similarly, diffusing capacity impairment is an independent predictor of the magnitude of radiologic emphysema (19), presence of resting hypoxemia, exercise-induced arterial oxygen desaturation (20), and functional impairment (21). Although we cannot say with certainty, this may reflect unique biologic processes (22). Other physiologic measures, such as hypercapnia, physiologic exercise impairment, or even measures of physical activity derived from actigraphy, may also reflect unique biological processes and consequently potential opportunities for unique therapeutic interventions $(23,24)$.

\section{Radiologic Characterization}

Quantitative assessment of emphysema by computed tomography (CT) scanning offers an objective measure of parenchymal disease that correlates well with histopathologic findings and is predictive of the degree of expiratory airflow obstruction (25). Objective measures of proximal airway wall thickening obtained via CT are inversely correlated with lung function and relate to a subject's burden of small airway disease (26) and exacerbation frequency (27). More recent work suggests that the correlative strength between CT measures of airway wall thickening and lung function increase when examining more distal fourth- and fifth-generation airways (28), although such structures approach the limits of accurate measurement using most currently available CT imaging reconstruction protocols and should therefore be used with caution.

Whether or not the presence of specific lung structural abnormalities (including emphysema, airway wall thickening, and/or bronchiectasis) predict meaningful clinical outcome is an area of current research interest $(29,30)$. Increasing emphysema severity as defined by CT has been associated with worse health status (27) and increased mortality (31). The National Emphysema Treatment Trial provides the most compelling evidence supporting distinct CT-based phenotypes in defining an increased risk of mortality in patients with homogenous emphysema and impaired $\mathrm{FEV}_{1}$ or diffusing capacity of carbon monoxide undergoing LVRS, whereas upper lobe-predominant emphysema and a low postrehabilitation exercise capacity identify a group of emphysema patients who experience a mortality and functional benefit from LVRS (16). These compelling data strongly support that a combination of CT imaging and physiological testing can clearly impact therapeutic decision making, thus validating its value as a phenotype according to our operational definition.

\section{COPD Exacerbations}

Within the framework we have proposed, an acute exacerbation of COPD (AECOPD) could be viewed as outcome or, in the context of describing a "frequent exacerbator," a phenotype. AECOPD is currently defined as: "A sustained worsening of the patient's condition, from the stable state and beyond normal day-to-day variations, that is acute in onset and necessitates a change in regular medication in a patient with underlying COPD" (32). This general description poses numerous operational challenges for use in clinical phenotyping. It remains unclear if these changes are quantitative or if there is also a qualitative element. Similarly, the normal variation in symptoms in patients with COPD remains relatively unexplored; how long changes in symptoms must be sustained before being characterized as an exacerbation varies according to study. Sputum color is a marker of bacterial-infective exacerbations that has validity in populations of patients (33). Although the consensus definition states: "necessitates a change in regular medication," the criteria invoked by health-care providers to judge when to alter medication remains unclear. Importantly, patient-recorded increases in symptoms that appear to be exacerbations outnumber those that cause them to present for medical attention (34). In addition, events with worsening symptoms that do not lead patients to seek additional care may, nevertheless, impact prognosis.

Despite limitations in defining AECOPDs, numerous investigators have highlighted the negative implications of these events in patients with COPD. Reviews of the published data confirm that AECOPDs exert significant short- and long-term negative effects on health-related QOL in patients with COPD (35). AECOPD episodes also result in modest, yet measurable, acute effects on pulmonary function (36). Perhaps most importantly, repeated AECOPDs have also been suggested to result in negative effects on longitudinal lung function (37) and can be identified by previous history of AECOPD (38), suggesting that patients with COPD with recurrent AECOPDs may reflect a distinct phenotypic group. This subgroup may be particularly relevant in consideration as a phenotype because it appears to be responsive to therapy with inhaled bronchodilators either alone or in combination with inhaled corticosteroids (39). Furthermore, a chronic bronchitic subgroup with sputum production and prior exacerbation history has recently identified a COPD cohort who experience improvement with the novel phosphodiesterase 4 inhibitor roflumilast (40). Here we have an example of targeting a drug for a specific COPD subpopulation that was identified by post hoc analysis of prospectively collected data from well-conducted clinical trials. This methodology may have value when considering variables not defined by therapeutic responses and is analogous to the widely adopted approach of identifying and then confirming genotypic information in replicate data sets. Post hoc analysis of well-done, prospective, placebo-controlled clinical trials conducted in patients with COPD with a range of disease severity and symptoms may be a fertile area in which to conduct responder analyses. This method of retrospective analysis may help to uncover patient attributes that indicate differential responses to treatment and may lead to the discovery of separate COPD clinical phenotypes potentially linked with molecular fingerprints of disease pathogenesis.

\section{Systemic Inflammation}

The presence of systemic inflammation may represent a unique COPD phenotype.

If defined by the presence of elevated biomarkers (including C-reactive protein, serum amyloid A, proinflammatory cytokines IL-6 and IL-8, tumor necrosis factor $\alpha$, and leukocytes), systemic inflammation does not appear to be present in every patient with COPD $(41,42)$. In fact, the prevalence of systemic inflammation in COPD appears to vary significantly depending on the particular marker (or combination of markers) chosen. Evidence of systemic inflammation can also be detected in 
patients who appear otherwise clinically stable $(41,42)$ but with evidence of further increase during exacerbations (43). Additionally, the presence of systemic inflammation does not appear to be unique to COPD but also occurs in other chronic diseases and even during normal aging. As it relates to phenotyping, thus far no clear relationship between systemic inflammation and a particular aspect of COPD (such as the severity of airflow limitation or the presence of emphysema, airway colonization, arterial hypoxemia, comorbidities, or symptoms), has clearly emerged. Thus, at this point in time it is unclear what mechanisms drive the presence, type, and/or severity of systemic inflammation in any given patient. It is also unclear whether therapy aimed at optimizing pulmonary function in COPD results in a reduction of systemic inflammation in these patients $(44,45)$ or whether the direct targeting of systemic inflammation influences the natural history of COPD.

\section{Comorbidities}

Patients with COPD often present with comorbid diseases, including cardiovascular disease, metabolic syndrome, osteoporosis, depression, and skeletal muscle wasting and dysfunction $(46,47)$. Systemic inflammation may contribute to the development of comorbid conditions and these disorders can be seen as manifestations of COPD or vice versa (48). Accelerated aging is a further process that could account for both the local lung effects of COPD and its comorbidities (49). Aging is characterized by a progressive, generalized impairment of function and amplification of the inflammatory response (50) that results in an increased vulnerability to environmental challenge and an increased risk of disease. The presence of many of these comorbidities appears to have a deleterious effect on several outcomes in COPD (51). In particular, diabetes, hypertension, cardiovascular disease, and cancer increase the risk of death in COPD (51). However, whether treatment of comorbid conditions alters the natural history of COPD or whether treatment of COPD is altered by the presence of a concomitant comorbidity awaits further study.

\section{MULTIDIMENSIONAL INDICES}

Recently several multidimensional indices have been described for prognostic purposes in COPD. Perhaps best well known of these is the BODE Index to predict mortality, which incorporates dyspnea, BMI, $\mathrm{FEV}_{1}$, and exercise capacity as measured by 6-minute walk distance (6MWD). Modifications of the BODE index have also been described, including the $\mathrm{mBODE}$ (replaces 6MWD with $\dot{\mathrm{V}}_{2}$ ) (52), e-BODE (BODE plus exac- erbations) (53), and BODE-x (substitution of exacerbations for exercise capacity) (53), as well as the ADO index (dyspnea, $\mathrm{FEV}_{1}$, and age), which are all better predictors of mortality in COPD than $\mathrm{FEV}_{1}$ alone $(6,54)$. Other indices that have been described include the COPD Prognostic Index (QOL, FEV age, sex, BMI, exacerbation history, cardiovascular disease history) (55) that predicts mortality, hospitalization, and exacerbation frequency, the SAFE Index (QOL, FEV 1 , 6MWD) (56) to predict exacerbation frequency, and the DOSE Index (dyspnea, smoking status, $\mathrm{FEV}_{1}$, and prior exacerbation history), which also predicts exacerbations (57). From the standpoint of clinical phenotyping, such multidimensional indices are useful in their ability to group patients in terms of clinically relevant outcomes. However, from a research standpoint, a note of caution is warranted. Although it is possible that the seemingly diverse measures included in a multidimensional index actually relate to a shared latent variable responsible for the clinical presentation, it is also possible that by grouping patients in this fashion we may be blurring distinct features of the disease that may hamper our understanding of the biologic or physiologic basis for the shared outcome.

\section{WHERE DO WE GO FROM HERE?}

The identification of COPD phenotypes will require an iterative validation process in which candidate phenotypes are identified before their relevance to clinical outcome is determined (Figure $1)$. As research is currently advancing on all fronts simultaneously, there are multiple points of entry into this process of phenotype identification (see Figure 1). Borrowing from the field of breast cancer, initially hormone-based therapies were tested in the general breast cancer population, but it was ultimately determined that that the presence of estrogen and progesterone receptors within the tumor determined the response to therapy (58). In asthma, cellular phenotypes of asthma (eosinophilic, neutrophilic, and paucigranulocytic) were identified by analyses of sputum and subsequently used to direct the successful application of mepolizumab (anti-IL-5) therapy (59). In COPD, roflumilast was initially studied in a general COPD population, but it was ultimately determined that it is a subpopulation of patients $\left(\mathrm{FEV}_{1}<50 \%\right.$ predicted, chronic cough, and sputum production) who demonstrate the greatest clinical response. Mechanistic studies, however, will be needed to understand the biologic basis for response in this subgroup.

From a practical standpoint, validation of phenotypes in COPD will require longitudinal data collection in carefully characterized patient populations. Studies such as Evaluation

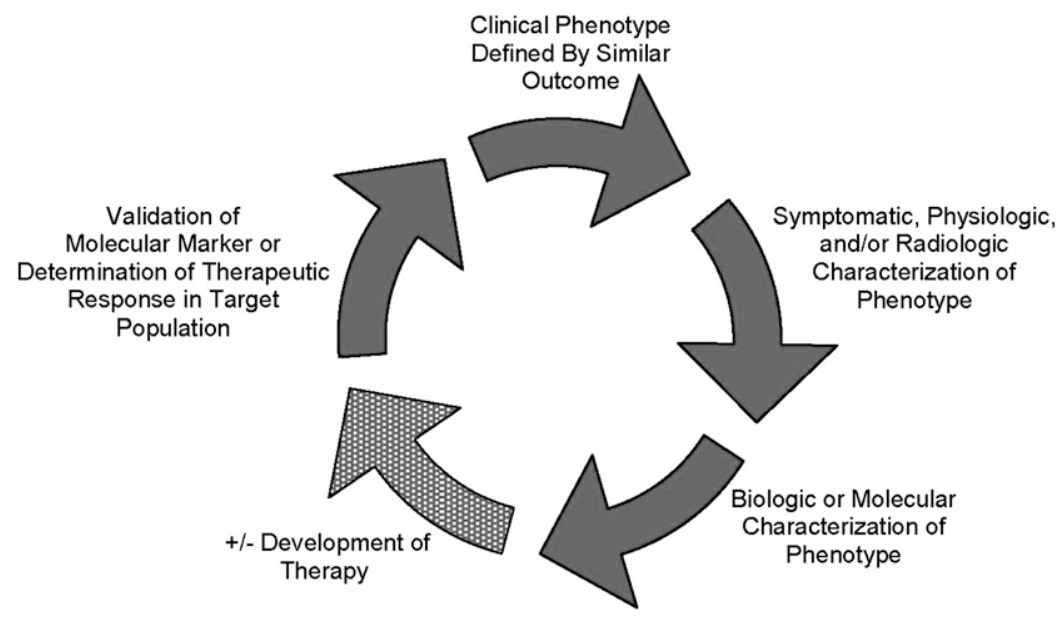

Figure 1. Ideal phenotyping construct wherein candidate phenotypes are validated once their relevance to clinical outcomes is established. There are multiple potential points of entry into this iterative process of phenotype identification. For instance, similar clinical outcomes may define a subpopulation that leads to the identification of a biologic target and focused therapy. Alternatively, the process might begin with the differentiation of subgroups based on a biologic marker that is then validated by similar clinical response within subgroups. 
of COPD Longitudinally to Identify Predictive Surrogate Endpoints (ECLIPSE), Subpopulations and intermediate outcome measures in COPD (SPIROMICS), and COPDGene that are systematically gathering clinical, physiologic, radiologic, biologic, and genetic data on COPD subjects will aid in this regard. Additionally, advanced statistical techniques may also prove useful in identifying candidate phenotypic subgroups. One such example is cluster analysis, which has a basis both in mathematics and biology and is a technique for data exploration. Cluster analysis encompasses a number of different algorithms for grouping subjects without an a priori hypothesis. A related statistical technique, factor analysis, may also prove useful in COPD phenotyping. Although the goal of cluster analysis is to reduce the number of observations or cases by grouping them into a smaller set of clusters, the goal of factor analysis is to reduce the number of variables by grouping them into a smaller set of factors. Cluster and factor analysis have been used in conjunction in COPD to identify key variables on which to select clusters of related patients (60-63). These types of analyses would still, however, require longitudinal validation to determine how such clustered subjects differ with respect to important clinical outcomes. In addition, such analyses may or may not ultimately be useful in defining specific biologic pathways or therapies.

The suggested schema for phenotype identification, however, represents an ideal construct, as almost every outcome measure other than death displays inherent difficulties with measurement. Furthermore, for every phenotype, a specific therapy may not be ultimately identified. An individual's phenotype may not be readily apparent at an early stage of disease. It may also be that any one individual has the potential to express a range of phenotypes that are ultimately determined by the individual's unique biology and exposures. Finally, it should be recognized that most cellular functions (and their perturbations in disease states) are performed by a complex network of genes, proteins, and metabolites that interact through biochemical and physical interactions. The new field of systems biology has begun to relate these "omic" networks to disease networks (comorbidities) and even social networks (smoking, obesity). Consequently, the concept of a "diseasome," linking cellular networks and phenotypic manifestations, is beginning to emerge. Such research strategies may also prove valuable in identifying relevant and novel phenotypes in COPD.

Author Disclosure: M.K.H. received up to $\$ 1,000$ from Novartis in consultancy fees, $\$ 1,001-\$ 5,000$ from CSL Behring in advisory board fees, $\$ 5,001-\$ 10,000$ from GlaxoSmithKline in lecture fees, and up to $\$ 1,000$ from UpToDate in royalties. A.A. received $\$ 5,001-\$ 10,000$ from GlaxoSmithKline, $\$ 5,001-\$ 10,000$ from Almirall, and $\$ 5,001-\$ 10,000$ from Nycomed in advisory board fees; $\$ 5,001-\$ 10,000$ from GlaxoSmithKline, \$5,001-\$10,000 from AstraZeneca, and $\$ 5,001-\$ 10,000$ from Almirall in lecture fees; and more than $\$ 100,001$ from GlaxoSmithKline, $\$ 10,001-\$ 50,000$ from Pfizer, $\$ 5,001-\$ 10,000$ from Boehringer Ingelheim, and more than $\$ 100,001$ from Almirall in industrysponsored grants. P.M.C. received $\$ 5,001-\$ 10,000$ from Pfizer, $\$ 1,001-$ $\$ 5,000$ from AstraZeneca, and $\$ 5,001-\$ 10,000$ from Chiesi in consultancy fees; $\$ 5,001-\$ 10,000$ from GlaxoSmithKline in advisory board fees; $\$ 1,001-\$ 5,000$ from Altana and $\$ 10,001-\$ 50,000$ from GlaxoSmithKline in lecture fees; and $\$ 10,001-\$ 50,000$ from Nycomed, $\$ 50,001-\$ 100,000$ from GlaxoSmithKline, and $\$ 10,001-\$ 50,000$ from Boehringer Ingelheim in industry-sponsored grants. B.R.C. does not have a financial relationship with a commercial entity that has an interest in the subject of this manuscript. G.C. received $\$ 1,001-\$ 5,000$ from Boehringer Ingelheim, $\$ 1,001-\$ 5,000$ from GlaxoSmithKline, and $\$ 1,001-$ $\$ 5,000$ from Aeris in industry-sponsored grants for a research study. J.L.C. received $\$ 1,001-\$ 5,000$ from AstraZeneca in honorarium for a nonpromotional lecture (November 2007), and $\$ 10,001-\$ 50,000$ from Boehringer Ingelheim in industry-sponsored grants (BI Protocol 205.325, which ended September 30, 2008). L.M.F. received $\$ 10,001-\$ 50,000$ from Nycomed, $\$ 10,001-\$ 50,000$ from GlaxoSmithKline, $\$ 10,001-\$ 50,000$ from Merck Sharpe \& Dohme, $\$ 10,001-\$ 50,000$ from Sigma-Tau, $\$ 10,001-\$ 50,000$ from AstraZeneca, $\$ 50,001-\$ 100,000$ from Boehringer Ingelheim, and $\$ 50,001-\$ 100,000$ from Chiesi Farmaceutici in consultancy fees; $\$ 1,001-\$ 5,000$ from Nycomed, $\$ 1,001-$ $\$ 5,000$ from AstraZeneca, $\$ 1,001-\$ 5,000$ from Abbott, $\$ 1,001-\$ 5,000$ from Boehringer Ingelheim, $\$ 1,001-\$ 5,000$ from Chiesi Farmaceutici, $\$ 1,001-\$ 5,000$ from GlaxoSmithKline, $\$ 1,001-\$ 5,000$ from Merck Sharp \& Dohme, $\$ 1,001-$ $\$ 5,000$ from Novartis, $\$ 1,001-\$ 5,000$ from UCB, $\$ 1,001-\$ 5,000$ from Roche, and $\$ 1,001-\$ 5,000$ from Pfizer in advisory board fees; $\$ 1,001-\$ 5,000$ from AstraZeneca, $\$ 1,001-\$ 5,000$ from Abbott, $\$ 1,001-\$ 5,000$ from Boehringer Ingelheim, $\$ 1,001-\$ 5,000$ from Chiesi Farmaceutici, $\$ 1,001-\$ 5,000$ from GlaxoSmithKline, $\$ 1,001-\$ 5,000$ from Merck Sharp \& Dohme, $\$ 1,001-\$ 5,000$ from Novartis, $\$ 1,001-\$ 5,000$ from Sigma-Tau, $\$ 1,001-\$ 5,000$ from UCB, $\$ 1,001-\$ 5,000$ from Roche, and $\$ 1,001-\$ 5,000$ from Pfizer in lecture fees. L.M.F.'s dependent received $\$ 50,001-\$ 100,000$ from Nycomed, $\$ 50,001-$ $\$ 100,000$ from Abbott, $\$ 50,001-\$ 100,000$ from AstraZeneca, $\$ 50,001$ $\$ 100,000$ from Boehringer Ingelheim, $\$ 50,001-\$ 100,000$ from Menarini, $\$ 50,001-\$ 100,000$ from Schering Plough, $\$ 50,001-\$ 100,000$ from Chiesi Farmaceutici, $\$ 50,001-\$ 100,000$ from Sigma-Tau, $\$ 50,001-\$ 100,000$ from Novartis, $\$ 50,001-\$ 100,000$ from GlaxoSmithKline, $\$ 50,001-\$ 100,000$ from Merck Sharp \& Dohme, $\$ 50,001-\$ 100,000$ from UCB, and $\$ 50,001-$ $\$ 100,000$ from Pfizer in industry-sponsored grants. J.G.G. received more than $\$ 100,001$ from MedQIA in an industry-sponsored grant. P.W.J. received $\$ 5,001-$ $\$ 10,000$ from GlaxoSmithKline, $\$ 1,001-\$ 5,000$ from Almirall, $\$ 5,001-\$ 10,000$ Spiration, and $\$ 5,001-\$ 10,000$ from Novartis in consultancy fees; $\$ 5,001-$ $\$ 10,000$ from GlaxoSmithKline, $\$ 5,001-\$ 10,000$ from Almirall, $\$ 1,001-\$ 5,000$ from AstraZeneca, $\$ 1,001-\$ 5,000$ from Roche, and $\$ 5,001-\$ 10,000$ from Spiration in advisory board fees; and $\$ 10,001-\$ 50,000$ from GlaxoSmithKline and $\$ 1,001-\$ 5,000$ from AstraZeneca in lecture fees. W.M. received $\$ 1,001-$ $\$ 5,000$ from Pfizer Pharmaceuticals in consultancy fees, $\$ 1,001-\$ 5,000$ from GlaxoSmithKline and $\$ 1,001-\$ 5,000$ from Pfizer in advisory board fees, $\$ 5,001$ $\$ 10,000$ from GlaxoSmithKline and $\$ 5,001-\$ 10,000$ from AstraZeneca in lecture fees, and more than $\$ 100,001$ from GlaxoSmithKline and more than $\$ 100,001$ from Pfizer in industry-sponsored grants. B.J.M. does not have a financial relationship with a commercial entity that has an interest in the subject of this manuscript. K.F.R. received $\$ 10,001-\$ 50,000$ from Nycomed and $\$ 5,001-$ $\$ 10,000$ from Forest in consultancy fees; $\$ 5,001-\$ 10,000$ from AstraZeneca, $\$ 5,001-\$ 10,000$ from Boehringer Ingelheim, $\$ 5,001-\$ 10,000$ from Chiesi, $\$ 5,001-\$ 10,000$ from Novartis, and $\$ 1,001-\$ 5,000$ from Pearl in advisory board fees; $\$ 1,001-\$ 5,000$ from Merck Sharpe and Dohme, $\$ 1,001-\$ 5,000$ from GlaxoSmithKline, $\$ 1,001-\$ 5,000$ from Chiesi, and $\$ 1,001-\$ 5,000$ from Boehringer Ingelheim in lecture fees; and $\$ 5,001-\$ 10,000$ from Nycomed and $\$ 5,001-\$ 10,000$ from Forest for serving as an expert witness. K.F.R.'s dependent received more than $\$ 100,001$ from Chiesi, $\$ 50,001-\$ 100,000$ from AstraZeneca, more than $\$ 100,001$ from Boehringer Ingelheim, and $\$ 10,001-\$ 50,000$ from Novartis in industry-sponsored grants. S.I.R. received $\$ 1,001-\$ 5,000$ from Able Associates, up to $\$ 1,000$ from Adelphi Research, $\$ 10,001-\$ 50,000$ from Almirall/Prescott, $\$ 1,001-\$ 5,000$ from APT Pharma/Britnall, $\$ 1,001-\$ 5,000$ from Aradigm, $\$ 1,001-\$ 5,000$ from AstraZeneca, $\$ 5,001-\$ 10,000$ from Boehringer Ingelheim, up to $\$ 1,000$ from Chiesi, up to $\$ 1,000$ from Common Health, up to $\$ 1,000$ from Consult Complete, $\$ 1,001-\$ 5,000$ from COPDForum, up to $\$ 1,000$ from Data Monitor, up to $\$ 1,000$ from Decision Resources, up to $\$ 1,000$ from Defined Health, $\$ 1,001-\$ 5,000$ from Dey, up to $\$ 1,000$ from Dunn Group, up to $\$ 1,000$ from Eaton Associates, up to $\$ 1,000$ from Equinox, up to $\$ 1,000$ from Gerson, $\$ 10,001-\$ 50,000$ from GlaxoSmithKline, up to $\$ 1,000$ from Infomed, up to $\$ 1,000$ from KOL Connection, up to $\$ 1,000$ from M. Pankove, up to $\$ 1,000$ from MedaCorp, up to $\$ 1,000$ from MDRx Financial, up to $\$ 1,000$ from Mpex, $\$ 10,001-\$ 50,000$ from Novartis, $\$ 10,001-\$ 50,000$ from Nycomed, $\$ 1,001-\$ 5,000$ from Oriel Therapeutics, $\$ 1,001-\$ 5,000$ from Otsuka, up to $\$ 1,000$ from Pennside Partners, $\$ 5,001-\$ 10,000$ from Pfizer (Varenicline), up to $\$ 1,000$ from PharmaVentures, $\$ 1,001-\$ 5,000$ from Pharmaxis, up to $\$ 1,000$ from Price Waterhouse, up to $\$ 1,000$ from Propagate, up to $\$ 1,000$ from Pulmatrix, up to $\$ 1,000$ from Reckner Associates, up to $\$ 1,000$ from Recruiting Resources, $\$ 1,001-\$ 5,000$ from Roche, up to $\$ 1,000$ from Schlesinger Medical, up to $\$ 1,000$ from Scimed, up to $\$ 1,000$ from Sudler and Hennessey, $\$ 1,001-$ $\$ 5,000$ from TargeGen, $\$ 1,001-\$ 5,000$ from Theravance, $\$ 1,001-\$ 5,000$ from UBS, $\$ 1,001-\$ 5,000$ from Uptake Medical, and $\$ 5,001-\$ 10,000$ from Vantage Point Mgmt in consultancy advisory board fees; $\$ 10,001-\$ 50,000$ from AstraZeneca, $\$ 5,001-\$ 10,000$ from Boehringer Ingelheim, $\$ 10,001-\$ 50,000$ from Creative Educational Concept, $\$ 5,001-\$ 10,000$ from the France Foundation, $\$ 1,001-\$ 5,000$ from Information TV, $\$ 1,001-\$ 5,000$ from the Network for Continuing Ed, $\$ 10,001-\$ 50,000$ from Novartis, $\$ 1,001-\$ 5,000$ from Pfizer, and $\$ 1,001-\$ 5,000$ from SOMA in lecture fees; $\$ 50,001-\$ 100,000$ from AstraZeneca, $\$ 50,001-\$ 100,000$ from Biomarck, $\$ 50,001-\$ 100,000$ from Centocor, $\$ 50,001-\$ 100,000$ from Mpex, $\$ 50,001-\$ 100,000$ from Nabi, $\$ 50,001-$ $\$ 100,000$ from Novartis, and $\$ 50,001-\$ 100,000$ from Otsuka in industrysponsored grants. S.I.R. filed provisional patent applications from the University of Nebraska Medical Center covering microRNA applications for the treatment of diseases (currently marketing to various commercial entities). S.I.R. received funding from RJ Reynolds to evaluate the effect of a harm reduction product in normal smokers (1996) and in subjects with chronic bronchitis (1999) and to assess the effect of smoking cessation on lower respiratory tract inflammation (2000); participated in a Philip Morris multicenter study to assess biomarkers of smoke exposure (2002); received funding for a clinical trial from the Institute for Science and Health (2005), which receives support from the tobacco industry, to evaluate biomarkers in exhaled breath associated with smoking cessation and reduction. This study was supplemented with funding from Lorillard and RJ Reynolds. S.I.R. received a grant from the Philip Morris External Research Program (2005) to assess the impact of cigarette smoking on circulating stem cells in the mouse. S.I.R. has consulted with RJ Reynolds on the topic of harm reduction until 2007, but did not receive personal remuneration for this. There are no active tobacco industry-funded projects. All ties with tobacco industry 
companies and entities supported by tobacco companies were terminated in 2007. F.C.S. received $\$ 1,001-\$ 5,000$ from Pfizer in consultancy fees, $\$ 1,001$ $\$ 5,000$ from GlaxoSmithKline, $\$ 1,001-\$ 5,000$ from AstraZeneca, \$1,001$\$ 5,000$ from Merck, and $\$ 1,001-\$ 5,000$ from PneumRx in advisory board fees, and more than $\$ 100,001$ from GlaxoSmithKline, more than $\$ 100,001$ from Pfizer and more than $\$ 100,001$ from Boehringer Ingelheim in industry-sponsored grants. E.K.S. received $\$ 10,001-\$ 50,000$ from GlaxoSmithKline and $\$ 10,001-$ $\$ 50,000$ from AstraZeneca in consultancy fees; $\$ 1,001-\$ 5,000$ from GlaxoSmithKline, $\$ 5,001-\$ 10,000$ from AstraZeneca, and $\$ 1,001-\$ 5,000$ from Bayer in lecture fees; and more than $\$ 100,001$ from GlaxoSmithKline in industrysponsored grants. J.V. received $\$ 10,001-\$ 50,000$ from GlaxoSmithKline, $\$ 1,001-\$ 5,000$ from Boehringer Ingelheim, $\$ 1,001-\$ 5,000$ from AstraZeneca, $\$ 1,001-\$ 5,000$ from Nycomed, and $\$ 1,001-\$ 5,000$ from Hoffman LaRoche in consultancy fees; $\$ 5,001-\$ 10,000$ from GlaxoSmithKline, $\$ 5,001-\$ 10,000$ from Boehringer-Ingelheim, \$5,001-\$10,000 from AstraZeneca, \$5,001-\$10,000 from Nycomed, and \$1,001-\$5,000 from Talecris in lecture fees; and more than $\$ 100,001$ from GlaxoSmithKline in industry-sponsored grants for the ECLIPSE study and HP-He substudy. G.R.W. received $\$ 1,001-\$ 5,000$ from Medlmmune in consultancy fees. E.F.M.W. received $\$ 1,001-\$ 5,000$ from Nycomed in advisory board fees; up to $\$ 1,000$ from GlaxoSmithKline, up to $\$ 1,000$ from AstraZeneca, and up to $\$ 1,000$ from Novartis in lecture fees; and more than $\$ 100,001$ from GlaxoSmithKline and more than $\$ 100,001$ from AstraZeneca in industry-sponsored grants; F.J.M. does not have a financial relationship with a commercial entity that has an interest in the subject of this manuscript.

\section{References}

1. Rabe KF, Hurd S, Anzueto A, Barnes PJ, Buist SA, Calverley P, Fukuchi Y, Jenkins C, Rodriguez-Roisin R, van Weel C, et al. Global strategy for the diagnosis, management, and prevention of chronic obstructive pulmonary disease: Gold executive summary. Am J Respir Crit Care Med 2007;176:532-555.

2. Rice JP, Saccone NL, Rasmussen E. Definition of the phenotype. $A d v$ Genet 2001;42:69-76.

3. Friedlander AL, Lynch D, Dyar LA, Bowler RP. Phenotypes of chronic obstructive pulmonary disease. COPD 2007;4:355-384.

4. Fletcher C, Peto R. The natural history of chronic airflow obstruction. BMJ 1977; 1:1645-1648.

5. Han MK, Postma D, Mannino DM, Giardino ND, Buist S, Curtis JL, Martinez FJ. Gender and chronic obstructive pulmonary disease: why it matters. Am J Respir Crit Care Med 2007;176:1179-1184.

6. Celli BR, Cote CG, Marin JM, Casanova C, Montes de Oca M, Mendez RA, Pinto Plata V, Cabral HJ. The body-mass index, airflow obstruction, dyspnea, and exercise capacity index in chronic obstructive pulmonary disease. N Engl J Med 2004;350:1005-1012.

7. Jennings JH, Digiovine B, Obeid D, Frank C. The association between depressive symptoms and acute exacerbations of COPD. Lung 2009 187:128-135.

8. Dahlen I, Janson C. Anxiety and depression are related to the outcome of emergency treatment in patients with obstructive pulmonary disease. Chest 2002;122:1633-1637.

9. Mahler DA, Ward J, Fierro-Carrion G, Waterman L, Lentine TF, MeijaAlfaro R, Baird JC. Development of self-administered versions of the modified baseline and transition dyspnea indexes in COPD. COPD 2004;1:145-172.

10. Jones PW. Health status measurement in chronic obstructive pulmonary disease. Thorax 2001;56:880-887.

11. Brown CD, Benditt JO, Sciurba FC, Lee SM, Criner GJ, Mosenifar Z, Shade DM, Slivka WA, Wise RA. Exercise testing in severe emphysema: association with quality of life and lung function. COPD 2008;5:117-124.

12. Wise RA. The value of forced expiratory volume in 1 second decline in the assessment of chronic obstructive pulmonary disease progression. Am J Med 2006;119:4-11.

13. Devanarayan V, Scholand MB, Hoidal J, Leppert MF, Crackower MA, O'Neill GP, Gervais FG. Identification of distinct plasma biomarker signatures in patients with rapid and slow declining forms of COPD. COPD 2010;7:51-58.

14. Han MK, Wise R, Mumford J, Sciurba F, Criner GJ, Curtis JL, Murray S, Sternberg A, Weinman G, Kazerooni E, et al. Prevalence and clinical correlates of bronchoreversibility in severe emphysema. Eur Respir J 2009;35:1048-1056.

15. Kesten S, Rebuck AS. Is the short-term response to inhaled betaadrenergic agonist sensitive or specific for distinguishing between asthma and COPD? Chest 1994;105:1042-1045.

16. Fishman A, Martinez F, Naunheim K, Piantadosi S, Wise R, Ries A, Weinmann G, Wood DE. A randomized trial comparing lungvolume-reduction surgery with medical therapy for severe emphysema. N Engl J Med 2003;348:2059-2073.
17. Casanova C, Cote C, de Torres JP, Aguirre-Jaime A, Marin JM, PintoPlata V, Celli BR. Inspiratory-to-total lung capacity ratio predicts mortality in patients with chronic obstructive pulmonary disease. Am J Respir Crit Care Med 2005;171:591-597.

18. O'Donnell DE, Lam M, Webb KA. Spirometric correlates of improvement in exercise performance after anticholinergic therapy in chronic obstructive pulmonary disease. Am J Respir Crit Care Med 1999;160: 542-549.

19. Gelb AF, Hogg JC, Muller NL, Schein MJ, Kuei J, Tashkin DP, Epstein JD, Kollin J, Green RH, Zamel N, et al. Contribution of emphysema and small airways in COPD. Chest 1996;109:353-359.

20. Owens GR, Rogers RM, Pennock BE, Levin D. The diffusing capacity as a predictor of arterial oxygen desaturation during exercise in patients with chronic obstructive pulmonary disease. $N$ Engl J Med 1984;310:1218-1221.

21. Dillard TA, Piantadosi S, Rajagopal KR. Determinants of maximum exercise capacity in patients with chronic airflow obstruction. Chest 1989;96:267-271.

22. Pinto-Plata V, Toso J, Lee K, Park D, Bilello J, Mullerova H, De Souza MM, Vessey R, Celli B. Profiling serum biomarkers in patients with COPD: associations with clinical parameters. Thorax 2007;62:595-601.

23. Hersh CP, Demeo DL, Lazarus R, Celedon JC, Raby BA, Benditt JO, Criner G, Make B, Martinez FJ, Scanlon PD, et al. Genetic association analysis of functional impairment in chronic obstructive pulmonary disease. Am J Respir Crit Care Med 2006;173:977-984.

24. Watz H, Waschki B, Boehme C, Claussen M, Meyer T, Magnussen H. Extrapulmonary effects of chronic obstructive pulmonary disease on physical activity: a cross-sectional study. Am J Respir Crit Care Med 2008; 177:743-751.

25. Kinsella M, Muller NL, Abboud RT, Morrison NJ, DyBuncio A. Quantitation of emphysema by computed tomography using a "density mask" program and correlation with pulmonary function tests. Chest 1990;97:315-321.

26. Nakano Y, Muro S, Sakai H, Hirai T, Chin K, Tsukino M, Nishimura $\mathrm{K}$, Itoh $\mathrm{H}$, Pare $\mathrm{PD}$, Hogg $\mathrm{JC}$, et al. Computed tomographic measurements of airway dimensions and emphysema in smokers. Correlation with lung function. Am J Respir Crit Care Med 2000; 162:1102-1108.

27. Han MK, Bartholmai B, Liu LX, Murray S, Curtis JL, Sciurba FC, Kazerooni EA, Thompson B, Frederick M, Li D, et al. Clinical significance of radiologic characterizations in COPD. COPD 2009;6:459-467.

28. Hasegawa M, Nasuhara Y, Onodera Y, Makita H, Nagai K, Fuke S, Ito Y, Betsuyaku T, Nishimura M. Airflow limitation and airway dimensions in chronic obstructive pulmonary disease. Am J Respir Crit Care Med 2006;173:1309-1315.

29. Coxson HO, Mayo J, Lam S, Santyr G, Parraga G, Sin DD. New and current clinical imaging techniques to study chronic obstructive pulmonary disease. Am J Respir Crit Care Med 2009;180:588-597.

30. Bon J, Leader J, Weissfield J, Coxson H, Zheng B, Branch R, Kondragunta V, Lee J, Zhang Y, Choi A, et al. The influence of radiographic phenotype and smoking status on peripheral blood biomarker patterns in chronic obstructive pulmonary disease. 2009 August 31, 2009 [accessed 2009 December 10]. Available from: http:// dx.plos.org/10.1371/journal.pone.0006865

31. Martinez FJ, Foster G, Curtis JL, Criner G, Weinmann G, Fishman A, DeCamp MM, Benditt J, Sciurba F, Make B, et al. Predictors of mortality in patients with emphysema and severe airflow obstruction. Am J Respir Crit Care Med 2006;173:1326-1334.

32. Rodrigues-Roisin R. Towards a consensus definition for COPD exacerbations. Chest 2000;117:398s-401s.

33. Stockley RA, O'Brien C, Pye A, Hill SL. Relationship of sputum colour to nature and outpatient management of acute exacerbations of COPD. Chest 2000;117:1638-1645.

34. Seemungal TA, Donaldson GC, Paul EA, Bestall JC, Jeffries DJ, Wedzicha JA. Effect of exacerbation on quality of life in patients with chronic obstructive pulmonary disease. Am J Respir Crit Care Med 1998;157:1418-1422.

35. Doll H, Miravitlles M. Health-related QOL in acute exacerbations of chronic bronchitis and chronic obstructive pulmonary disease. A review of the literature. Pharmacoeconomics 2005;23:345-363.

36. Parker CM, Voduc N, Aaron SD, Webb KA, O'Donnell DE. Physiological changes during symptom recovery from moderate exacerbations of COPD. Eur Respir J 2005;26:420-428.

37. Silverman EK. Exacerbations in chronic obstructive pulmonary disease: do they contribute to disease progression? Proc Am Thorac Soc 2007; 4:586-590. 
38. Niewoehner DE, Collins D, Erbland ML. Relation of FEV(1) to clinical outcomes during exacerbations of chronic obstructive pulmonary disease. Department of Veterans Affairs Cooperative Study Group. Am J Respir Crit Care Med 2000;161:1201-1205.

39. Ferguson GT, Anzueto A, Fei R, Emmett A, Knobil K, Kalberg C. Effect of fluticasone propionate/salmeterol $(250 / 50 \mathrm{microg})$ or salmetero (50 microg) on COPD exacerbations. Respir Med 2008;102:1099-1108.

40. Calverley PM, Rabe KF, Goehring UM, Kristiansen S, Fabbri LM, Martinez FJ. Roflumilast in symptomatic chronic obstructive pulmonary disease: two randomised clinical trials. Lancet 2009;374:685-694.

41. Agusti AG, Noguera A, Sauleda J, Sala E, Pons J, Busquets X. Systemic effects of chronic obstructive pulmonary disease. Eur Respir J 2003; 21:347-360.

42. Gan WQ, Man SF, Senthilselvan A, Sin DD. Association between chronic obstructive pulmonary disease and systemic inflammation: a systematic review and a meta-analysis. Thorax 2004;59:574-580.

43. Hurst JR, Perera WR, Wilkinson TM, Donaldson GC, Wedzicha JA. Systemic and upper and lower airway inflammation at exacerbation of chronic obstructive pulmonary disease. Am J Respir Crit Care Med 2006;173:71-78.

44. Sin DD, Lacy P, York E, Man SF. Effects of fluticasone on systemic markers of inflammation in chronic obstructive pulmonary disease. Am J Respir Crit Care Med 2004;170:760-765.

45. Sin DD, Man SF, Marciniuk DD, Ford G, FitzGerald M, Wong E, York E, Mainra RR, Ramesh W, Melenka LS, et al. The effects of fluticasone with or without salmeterol on systemic biomarkers of inflammation in chronic obstructive pulmonary disease. Am J Respir Crit Care Med 2008;177:1207-1214.

46. Soriano JB, Visick GT, Muellerova H, Payvandi N, Hansell AL. Patterns of comorbidities in newly diagnosed COPD and asthma in primary care. Chest 2005;128:2099-2107.

47. Crisafulli E, Costi S, Luppi F, Cirelli G, Cilione C, Coletti O, Fabbri LM, Clini EM. Role of comorbidities in a cohort of patients with COPD undergoing pulmonary rehabilitation. Thorax 2008;63:487-492.

48. van Eeden SF, Sin DD. Chronic obstructive pulmonary disease: a chronic systemic inflammatory disease. Respiration 2008;75:224-238.

49. Ito K, Barnes PJ. COPD as a disease of accelerated lung aging. Chest 2009;135:173-180.

50. De Martinis M, Franceschi C, Monti D, Ginaldi L. Inflammation markers predicting frailty and mortality in the elderly. Exp Mol Pathol 2006;80:219-227.

51. Mannino DM, Thorn D, Swensen A, Holguin F. Prevalence and outcomes of diabetes, hypertension and cardiovascular disease in COPD. Eur Respir J 2008;32:962-969.
52. Cote CG, Pinto-Plata VM, Marin JM, Nekach H, Dordelly LJ, Celli BR. The modified BODE index: Validation with mortality in COPD. Eur Respir J 2008;32:1269-1274.

53. Soler-Cataluna JJ, Martinez-Garcia MA, Sanchez LS, Tordera MP, Sanchez PR. Severe exacerbations and BODE index: two independent risk factors for death in male COPD patients. Respir Med 2009; 103:692-699.

54. Puhan MA, Garcia-Aymerich J, Frey M, ter Riet G, Anto JM, Agusti AG, Gomez FP, Rodriguez-Roisin R, Moons KG, Kessels AG, et al. Expansion of the prognostic assessment of patients with chronic obstructive pulmonary disease: the updated BODE index and the ADO index. Lancet 2009;374:704-711.

55. Briggs A, Spencer M, Wang H, Mannino D, Sin DD. Development and validation of a prognostic index for health outcomes in chronic obstructive pulmonary disease. Arch Intern Med 2008;168:71-79.

56. Azarisman MS, Fauzi MA, Faizal MP, Azami Z, Roslina AM, Roslan H. The SAFE (SGRQ score, air-flow limitation and exercise tolerance) index: a new composite score for the stratification of severity in chronic obstructive pulmonary disease. Postgrad Med J 2007;83:492-497.

57. Jones RC, Donaldson GC, Chavannes NH, Kida K, Dickson-Spillmann M, Harding S, Wedzicha JA, Price D, Hyland ME. Derivation and validation of a composite index of severity in chronic obstructive pulmonary disease - the dose index. Am J Respir Crit Care Med 2009; 180:1189-1195.

58. Rakha EA, Ellis IO. Triple-negative/basal-like breast cancer. Pathology 2009;41:40-47. [Review].

59. Wenzel SE. Eosinophils in asthma-closing the loop or opening the door? N Engl J Med 2009;360:1026-1028.

60. Burgel PR, Paillasseur JL, Caillaud D, Tillie-Leblond I, Chanez P, Escamilla R, Court-Fortune I, Perez T, Carre P, Roche N. Clinical COPD phenotypes: a novel approach using principal component and cluster analyses. Eur Respir J 2010:Epub ahead of print Jan. 14.

61. Weatherall M, Travers J, Shirtcliffe PM, Marsh SE, Williams MV, Nowitz MR, Aldington S, Beasley R. Distinct clinical phenotypes of airways disease defined by cluster analysis. Eur Respir J 2009;34:812-818.

62. Paoletti M, Camiciottoli G, Meoni E, Bigazzi F, Cestelli L, Pistolesi M, Marchesi C. Explorative data analysis techniques and unsupervised clustering methods to support clinical assessment of chronic obstructive pulmonary disease (COPD) phenotypes. J Biomed Inform 2009; 42:1013-1021.

63. Cho MH, Washko GR, Hoffmann TJ, Criner GJ, Hoffman EA, Martinez FJ, Laird N, Reilly JJ, Silverman EK. Cluster analysis in severe emphysema subjects using phenotype and genotype data: an exploratory investigation. Respir Res 2010;11:30. 